\title{
An approach to engaging students in a large-enrollment, introductory STEM college course
}

\begin{abstract}
Robert J. Swap ${ }^{1}$ and Jonathan A. Walter ${ }^{2}$
Abstract: While it is clear that engagement between students and instructors positively affects learning outcomes, a number of factors make such engagement difficult to achieve in large-enrollment introductory courses. This has led to pessimism among some education professionals regarding the degree of engagement possible in these courses. In this paper we challenge this pessimistic outlook through a case study involving a large-enrollment introductory, general education, STEM college course. Several pedagogical approaches related to social constructivist theory offer possibilities for increasing student engagement in the learning process, but they may be difficult to implement, particularly in environments yielding little or no reward for classroom innovation. Here, we present an approach to developing an engaging learning environment by hybridizing aspects from a range of pedagogical approaches varying from the didactic (e.g. traditional lecture) to the more constructivist (e.g. peer instruction, project-based learning). We describe the course in question and our pedagogical approach, provide evidence for its effectiveness, and discuss contextual factors affecting the development of our approach and its adoption to other subjects and institutions. We also discuss important remaining challenges regarding the adoption of our approach and similar practices.
\end{abstract}

Keywords: large enrollment, STEM, student engagement, constructivism, hybrid

\section{Introduction}

A recent article posted on the website of the Chronicle of Higher Education entitled "A Caring Professor May Be Key in How a Graduate Thrives" touted the positive impact of engaged professors on the learning outcomes of their students (Carlson, 2014). While such findings are not necessarily new, what was interesting to the authors here, as co-instructors, was the insight gained from the thread of comments that followed, ostensibly largely from higher education professionals, discussing the pros and cons of the article. A commonly expressed opinion was that one couldn't have interactions in large introductory courses that would lead to the types of interpersonal engagement between students and professors that the article promoted.

As instructors of a large enrollment class, the remarks in the comment thread that followed the article spurred reflection on the idea that achieving relational engagement in large enrollment classes is not probable if even possible. In 2010, the lead instructor inherited an introductory, large enrollment course that was developed primarily on the "traditional" approach to such a course; that is, being highly didactic and overwhelmingly composed of lectures. After several semesters

\footnotetext{
${ }^{1}$ Department of Environmental Sciences, University of Virginia, Charlottesville, VA 22904; Unit for Environmental Science and Management, North-West University, Potchefstroom, South Africa, rjswap@gmail.com,

${ }^{2}$ Department of Environmental Sciences, University of Virginia, Charlottesville, VA 22904; Present address:

Department of Biology, Virginia Commonwealth University, Richmond, VA 23284
} 
of development by the lead instructor, we found ourselves teaching that course with a different approach, and by all accounts we were observing some evidence of success with respect to cultivating engagement among students and instructors, despite the large lecture format. This led to an introspective examination of how it is that we do what we do, culminating in this case study.

Even restricted to scholarly and educational contexts, the term "engaged" has many meanings (Christenson et al., 2003). Boyer and others, influentially, have considered the "scholarship of engagement" to describe how scholars work with and for communities, participating in activities that cross disciplinary boundaries, teaching, research, and outreach (e.g. Boyer, 1996; Barker, 2004). The article motivating this case study focused on relational aspects of engagement between students and instructors, but we take a slightly broader view that to a degree integrates with the "scholarship of engagement" promoted by Boyer and others. We find that relational engagement is associated with interest in and accessibility of course content and related themes, which is itself associated with students' perceptions of the applicability of course material to matters of civil discourse. As such, we treat interactions with students, classroom instruction, and opportunities to connect with a broader conversation outside the classroom as intrinsically linked and mutually reinforcing.

The aforementioned Carlson article is far from the only one to identify engagement between students and instructors as a positive influence on educational outcomes (e.g. Klem \& Connell, 2004; Umbach \& Wawrzynski, 2004; Jones, 2008). However, large introductory courses can pose numerous barriers to developing this sense of personal engagement (e.g. Cuseo, 2007; Mulryan-Kyne, 2010; Hornsby et al., 2013). While perceived by many to be cost-effective from an institutional perspective, large enrollments may place constraints on classroom activities and assessments, and the student body composition runs a higher probability of unevenness in prior knowledge and individual student motivation. Even though such large general introductory courses can be difficult to teach, they are also critically important. Particularly in the STEM fields, these types of courses cover subject material that many of today's college students need exposure to, not only to fulfill area requirements, but also to become well-rounded, informed citizens. More immediately, an engaging introductory course can inspire students to pursue further coursework within a major or minor. Consequently, as the integration of advances in educational psychology, new technologies, and economic realities are challenging "business as usual" in higher education, a critical problem is how to improve student outcomes and experiences in such high enrollment introductory courses. We believe that one significant barrier to improving engagement in these courses is the heavy emphasis on an instructor-centered classroom, within which instructors talk and students listen to receive the desired information (e.g. Ebert-May et al., 1997; Prosser \& Trigwell, 2014).

This paper aims to challenge the conventional wisdom that engagement cannot be achieved in large-enrollment introductory courses by sharing an approach to creating an engaging classroom environment in a large, introductory STEM course in conservation ecology. Conservation ecology is a dynamic field, focusing intently on connections and flows between components of coupled human-natural systems. It is also an intrinsically collaborative field, wherein offering a holistic introduction to the field requires going beyond transferring mere factual knowledge to exposing students to the teamwork and ancillary skills necessary for successful collaboration, and an appreciation of how each individual (and each issue) is connected to a larger context. As researchers who collaborate across disciplines and across the divide between academics and practitioners, it was a natural extension to scaffold this coursework with this type of systems thinking. As we refined our pedagogy and interacted with colleagues across the university, we 
came to realize that our approach is philosophically consistent with social constructivism (e.g. Vygotsky, 1978).

In an educational context, social constructivism implies that learning occurs via groups interacting through shared experience to co-develop knowledge and interpret the meaning and implications of the knowledge gained (e.g. Lave \& Wenger, 1991). Several pedagogical approaches reflecting characteristics of social constructivism have been developed elsewhere; these include Project-Oriented Guided Inquiry Learning (POGIL) (Moog \& Spencer, 2008), Problem-based learning (Savery \& Duffy, 1995; Savery, 2006), Project-based learning (Thomas, 2000; Dym et al., 2005; Bell, 2010), and Peer Instruction (Mazur, 1997). Such "student-centered" practices have yielded gains in student learning, and particularly in student motivation and interest, in a variety of educational contexts (Hein, 2012; Opdecam, et al. 2014; Conway, 2014). However, some researchers have noted faculty resistance to adopting these innovations related to perceptions about their practice and discipline or department norms, despite ample evidence of these approaches' effectiveness (Rogers, 2003; Gess-Newsome, et al. 2003; Bunce, et al. 2008; Mulryan-Kyne, 2010; Seymour, et al. 2011). Reasons for this faculty resistance include but are not limited to discomfort and anxiety with breaking away from traditional approaches; the additional work required in creating a more active learning environment; a lack of knowledge of alternative approaches; and the risk that the students may not be receptive to these new approaches (MulryanKyne, 2010). Furthermore, the investment of time and energy required to incorporate, evaluate and disseminate these new approaches as part of a faculty member's teaching portfolio is often perceived as not worth the return to that person's professional advancement. As Richlin (2001, p.61) effectively states, "the sad truth is that many departments and institutions do not count pedagogical scholarship as part of the faculty members' scholarly production."

In the fields of environmental sciences, sustainability science and development studies, there is an ever expanding number of calls for engaged scholarship that provides larger society with the necessary transdisciplinary research and education to contribute to the transformation, resilience and sustainability of our societies (e.g. Crow, 2010; Whitmer et al., 2010; Yarime et al., 2012). It is within this context that the spirit of this particular Conservation Ecology course was reconfigured. In spite of the aforementioned realities of regarding a lack of perceived value by units within institutions of Higher Education, we share our experiences with a hybridized approach to engaging students designed to increase the accessibility of course content.

Our approach is best described as a hybrid between a more traditional lecture format and adaptations of more recently developed pedagogical methods including the aforementioned "constructivist" pedagogies and the flipped classroom (Bergmann \& Sams, 2012; Herreid \& Schiller, 2013; Bishop \& Verleger, 2013). The efficacy of hybrid and adaptive approaches has been documented (Carrió et al., 2011; Chase et al., 2013). Carrió et al., (2011), for example, found that use of a hybrid problem-based learning approach to the teaching of biology resulted in no statistically significant differences in the acquisition of factual knowledge when compared to the use of more traditional lecture-based learning. However, with their hybrid approach Carrió et al. (2011) documented increased student satisfaction as well as an enhancement of critical thinking, cooperative work, information management, and communication skills when compared to a lecture-based classroom. We assert that our model creates opportunities for engagement between students and instructors in a large lecture environment and that this opportunity for increased engagement generates gains in student interest and satisfaction. Furthermore, we contend that our approach may be more easily implemented than wholesale adoption of other classroom innovations, owing to its flexibility, as has been noted elsewhere (e.g. Gidley, 2012).

Journal of the Scholarship of Teaching and Learning, Vol. 15, No. 5, October, 2015. Josotl.Indiana.edu 
Our intent is neither to denigrate nor to replace any pedagogical tools (e.g., POGIL, PBL, Peer Instruction, the flipped classroom) that have proven effective in other settings. Rather, we aim to present an approach that has been effective in our particular context as a means of sharing experiences and perspectives that might be of value to others. Our approach will be contextualized relative to our institution and grounded in the larger field of the scholarship of teaching and learning. In addition, quantitative and qualitative evidence supporting the effectiveness of the approach will be presented. Finally, we discuss key challenges faced by instructors of this and similar courses, as well as contextual factors that may affect the adaptation of our approach to other situations.

\section{Course Description and Contextual Factors}

The course, "Conservation Ecology: Biodiversity and Beyond," is a three credit-hour 2000-level course offered in the College of Arts and Sciences at the University of Virginia. It has been offered four times from 2010 to 2013 (one section each fall semester) and has met in both three days/week $\times 50$ minutes and two days/week $\times 75$ minutes formats during the middle of the day (either 13001350 or 1100-1215). In 2010-2012, the course was taught with a single instructor and in 2013 was co-taught between a professor and an experienced graduate teaching assistant while having the same lead instructor in all four years. The course is designed to meet the general science elective course requirements for students in the College of Arts and Sciences. Enrollment is ca. 180 students spanning a wide range of majors/intended majors and stages of their college career. See Table 1 for a statistical characterization of student composition. It is no secret that many students taking gen-ed science electives are looking for courses that appear to be (as one student put it) "less painful scientifically." However, there is also a segment of the student population in the course that is highly motivated, skilled, and deeply versed in issues of environmental science and ecology. A great challenge, therefore, is how to create an engaging classroom atmosphere given that the levels of prior understanding and degree of motivations are often quite disparate at the beginning of the semester.

Journal of the Scholarship of Teaching and Learning, Vol. 15, No. 5, October, 2015. 
Table 1: Statistical characterization of course student population. Total indicates the number of students that enrolled in the course. M:F indicates the ratio of male to female students. Majors are grouped by Humanities and Social Sciences, Physical and Natural Sciences, Other, and Undeclared. Majors grouped as "Other" include architecture, nursing, engineering, the Curry School of Education, the Batten School of Leadership and Public Policy and the McIntire School of Commerce.

\begin{tabular}{|c|c|c|c|c|c|c|c|c|c|c|}
\hline \multirow[b]{2}{*}{$\begin{array}{c}\text { Yea } \\
\mathrm{r}\end{array}$} & \multirow[b]{2}{*}{$\begin{array}{c}\text { Tota } \\
1\end{array}$} & \multirow[b]{2}{*}{$\mathrm{M}: \mathrm{F}$} & \multicolumn{4}{|c|}{ Academic Standing } & \multicolumn{4}{|c|}{ Major } \\
\hline & & & $\begin{array}{c}1^{\text {st }} \\
\text { Year }\end{array}$ & $\begin{array}{c}2^{\text {nd }} \\
\text { Year }\end{array}$ & $\begin{array}{c}3^{\text {rd }} \\
\text { Year }\end{array}$ & $\begin{array}{c}4^{\text {th }} \\
\text { Year }\end{array}$ & $\begin{array}{l}\text { Hum/ } \\
\text { Soc.Sc } \\
\text { i }\end{array}$ & $\begin{array}{c}\text { Phys/ } \\
\text { Nat. } \\
\text { Sci }\end{array}$ & Other & $\begin{array}{l}\text { Unde- } \\
\text { clared }\end{array}$ \\
\hline $\begin{array}{c}201 \\
0\end{array}$ & 176 & $\begin{array}{c}\text { 0.81: } \\
1\end{array}$ & $39.8 \%$ & $26.1 \%$ & $18.2 \%$ & $15.3 \%$ & $22.2 \%$ & $10.7 \%$ & $7.4 \%$ & $59.7 \%$ \\
\hline $\begin{array}{c}201 \\
1\end{array}$ & 207 & $\begin{array}{c}0.95: \\
1\end{array}$ & $30.9 \%$ & $33.8 \%$ & $23.2 \%$ & $12.1 \%$ & $29.5 \%$ & $10.1 \%$ & $2.9 \%$ & $57.5 \%$ \\
\hline $\begin{array}{c}201 \\
2\end{array}$ & 165 & $\begin{array}{c}0.74: \\
1\end{array}$ & $47.9 \%$ & $29.7 \%$ & $12.7 \%$ & $9.7 \%$ & $18.9 \%$ & $5.5 \%$ & $1.8 \%$ & $73.9 \%$ \\
\hline $\begin{array}{c}201 \\
3\end{array}$ & 166 & $\begin{array}{c}0.77: \\
1\end{array}$ & $34.3 \%$ & $30.1 \%$ & $18.7 \%$ & $16.3 \%$ & $21.1 \%$ & $10.2 \%$ & $6.0 \%$ & $62.7 \%$ \\
\hline
\end{tabular}

Factual content focuses on an introduction to key ecological concepts involved in making sound decisions about conservation at scales from the population to the global biosphere. We go beyond the traditional concept of conservation (i.e., the protection of an individual species) to focus on understanding the larger concepts and contexts of entire landscapes and the processes that support them. We highlight the complex and collaborative nature of conservation and use abundant group work to not only encourage critical thinking and expose students to skills needed for effective collaborations, but also to provide opportunities to model those skills. The course is structured to achieve the following learning goals: 1) make students aware that nature is constantly changing; 2) increase awareness and understanding of the concept of socio-ecological systems and their often non-linear and cyclical patterns; 3) make students aware of how they are connected to these systems and how these systems are connected to each other across various scales; 4) understand how changes to a system can impact other systems at different spatial and temporal scales; 5) develop collaboration and teamwork skills; and 6) for each student to have sufficient understanding of key concepts to be able to conduct fifteen minutes of intelligent conversation (i.e., "cocktail party conversation;" Lesgold, 1984) about ecological conservation.

\section{Pedagogical Approach}

As instructors, our overall goal is not merely facilitating the acquisition of knowledge, but rather encouraging their active participation and generating knowledge in a collaborative fashion, a goal more in line with the student centered approach described by Prosser \& Trigwell (2014). To accomplish this, we focused on the creation of a learning environment that fostered the exchange of information, critical thinking, and perhaps most importantly, encouraged engagement. In many ways what we aimed to do with our large classroom experience is what others in the field are trying to do in theirs: to move from the purely didactic toward a more student-centered learning environment fostering active learning (e.g. Gibbs, 1992; Biggs, 1999; Mulryan-Kyne, 2010).

Journal of the Scholarship of Teaching and Learning, Vol. 15, No. 5, October, 2015. 
Though our approach was born organically of the experiences of the authors as learners and teachers, we have (often unknowingly) adapted elements of pedagogical approaches associated with social constructivism such as POGIL, Problem-based and Project-based learning. While these individual methods have developed out of different fields and have certain unique features, common elements between these approaches include the use of cooperative social interactions to build conceptions of course material and a shift in the role of the instructor(s) toward that of facilitator as opposed to lecturer (Eberlein et al., 2008; Woods, 2013).

We have identified five key features of our approach that are summarized here and discussed in greater detail below: 1) use of small-group activities to facilitate student-student and student-instructor interactions in the classroom; 2) consideration of multiple perspectives and knowledge sources through the use of a diversity of instructional media; 3) leveling of the classroom hierarchy to invite broader participation; 4) creation of cognitive dissonance as a platform for engagement; and 5) high instructor availability to create opportunities for face-to-face interaction.

\section{Semester Structure}

The overarching semester structure of the course reflected a tradeoff between the objective of fostering critical thinking and the challenge of incoming students having a wide range of motivation and prior knowledge. Accordingly, we transitioned over a continuum from an initial condition in which the instructors carried the load with respect to the transfer of knowledge, to a final condition in which the students bore responsibility for acquiring and generating knowledge and sharing it with members of the course (Figure 1). At the beginning of the course, the instructors' initial focus was to introduce a common language around the field of conservation and to produce a common platform of student knowledge and engagement. Here, we leaned more heavily on lecture and in-class activities were more closely guided than later on in the course, though they were still used regularly to develop a participatory classroom environment. We emphasized key principles of the ubiquity of environmental change and the connectedness of ecological and socio-ecological systems through relevant case studies. The instructors purposefully endeavored to relate each concept to other majors/disciplines and areas of student interest, from personal economics to sociology to popular culture, demonstrating that there is much to learn from this course that is applicable to other areas of life. Consistent with our studentcentered philosophy, we encouraged students to begin making these connections independently by voluntarily sharing articles and news pieces that related to course concepts with the instructors. We frequently opened class sessions by discussing with the whole class current events that had been sent us by students. 


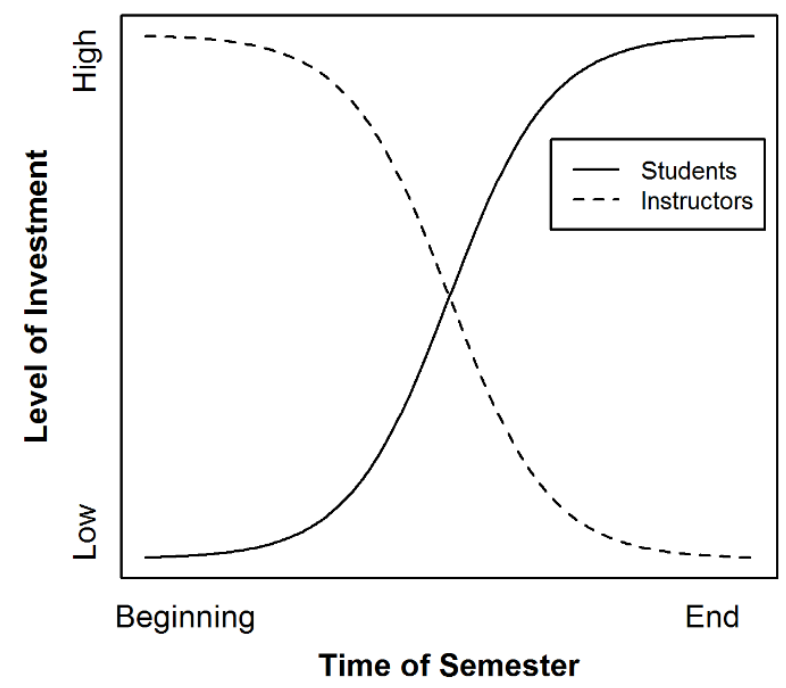

Figure 1. Illustration of how investment, or input, of instructors and students changes throughout the course.

During the middle of the course, the instructors began in earnest to transition toward the final condition in which students carry the load for acquiring and sharing knowledge. We found that a powerful tool in accomplishing this was to support students in embracing greater ownership of their learning. Although we continued some lecture to formalize new concepts, in-class activities gradually became more central to the course. The questions discussed also changed in nature from focusing on content comprehension to more complex modes of thinking. On reflection, our in-class activities somewhat resembled POGIL activities in that they guided students through a progression of concept formation and application, but were less open-ended than one might find in a Problem-Based Learning classroom.

Approximately halfway through the semester, the course took on characteristics of ProjectBased Learning as we introduced a final project in which groups of students collaboratively research a contemporary real-world environmental issue of their choosing and prepare a 10-minute presentation (in which all members speak) and short paper that describes the chosen issue, analyzes it in the context of key course concepts (such as ecosystem resilience, the adaptive cycle, and panarchy ${ }^{3}$ ), and suggests solutions that are informed by their knowledge of the connectedness of socio-ecological systems. One component of the project is the articulation of three to four key points that their fellow students should "take away" from their presentation. With this in mind, the students are aware from the outset that they have to keep the needs of the end user community front and center prior to the development of any project concept an approach referred to as people first, process second and then the product (Allen et al., 2014).

For the final project, the instructors assign student groups of approximately seven to eight students somewhat randomly, with adjustments made to ensure a general evenness of student ability and engagement between groups. Groups work together to propose ideas, which go through initial vetting via brief pitches of the idea in-class to an instructor one week after the project is

\footnotetext{
${ }^{3}$ An helpful text concerning the concepts of ecosystem resilience, the adaptive cycle, and panarchy is: Gunderson, L.H., \& Holling, C. S. (2001). Panarchy: Understanding Transformations in Human and Natural Systems. Washington, D.C.: Island Press.

Journal of the Scholarship of Teaching and Learning, Vol. 15, No. 5, October, 2015. Josotl.Indiana.edu
} 
introduced. During the following weeks, project groups also receive formal mentoring in at least one progress meeting between an instructor and each project group outside of class. These meetings consist of 30 to 60 minutes of back-and-forth discussion to aid student groups in formulating and articulating their ideas and to suggest additional lines of thinking and other areas for improvement.

By the end of the course, students have taken on the lion's share of responsibility for acquisition, processing, and transmission of collaboratively generated knowledge. The role of the instructors has shifted from being the predominate source of information/knowledge authority to largely one of mentoring student groups and supporting them through access to resources and as serving as sounding boards to provide critical feedback in the development of their final presentations. Lecture and in-class activities are tapered off and class time is mainly allocated to providing project teams with time to meet with each other and hold brief discussions with instructors. The semester culminates in two and a half weeks of formal student presentations, in which the students themselves fulfill the role of instructor/knowledge authority.

As stated previously, we had objectives for our students related to interpersonal connectedness and the development of skills to enhance collaboration and teamwork. As instructors, we firmly believe in the value of modeling these expected behaviors for our students. Not unlike those lecturers profiled in Bannink \& Van Dam (2013a), we had an objective to initiate the development of instructor-student relationships as early in the semester as possible, and it has been our experience that by developing these relationships early the students feel more confident in independently accessing educational resources as the semester progressed. We made ourselves available to students by arriving to the classroom early and lingering for a few minutes afterward. We also kept regular office hours; at least one co-instructor was available for at least one hour, four out of five days of the week. While office hours were not always used, they were always available, and we maintained this level of instructor availability throughout the semester.

\section{Course Materials}

One key feature of our approach is the use of a diversity of instructional media to present students with multiple perspectives and sources of knowledge. These included lectures, scholarly and popular texts, and videos. This diversity of instructional media underscores the validity of multiple perspectives and sources of knowledge, and also creates cognitive dissonance by presenting students with perspectives different from their own. We chose texts for the course that we believed students would find more accessible and engaging than a traditional textbook ${ }^{4}$. We assigned weekly readings from the two main course texts, and supplemented those readings with additional articles. These articles brought in additional perspectives regarding historical, social, and ethical perspectives on conservation. These readings seemed to speak to a large number of students, particularly non-science students who did not feel that the readings were intellectually intimidating. We also assigned short videos (e.g. TED talks, PBS Frontline presentations, etc.). These were used to provide additional perspectives and to introduce difficult concepts before other instructional activities (e.g. discussion, lecture, or additional reading) unpacked and clarified new

\footnotetext{
${ }^{4}$ Shugart, H. H. (2004). How the earthquake bird got its name and other tales of an unbalanced nature. New Haven, CT: Yale University Press; Walker, B., \&Salt, D. (2012). Resilience Practice. Washington, D.C.: Island Press.
} 
concepts. Assigned readings and videos frequently were the subject of small-group in-class activities.

\section{Class Sessions}

Class sessions were viewed as an opportunity to share knowledge, interact with our students, and encouraging their active participation. Additionally, we took an approach to lecture and group activities that attempted to take a large room and make it feel smaller. With respect to presentation of content, we purposefully took principles we were discussing on a given day and investigated relationships and analogies to them, often invoking systems that at first glance appear to have nothing in common with 'natural' systems. In retrospect, our approach was philosophically consistent with Nisbet et al.'s (2010) vision of how the 'four cultures' of environmental sciences, creative arts and professions, philosophy and religion and the social sciences can engage each other to facilitate new synergies to foster of more effective societal responses to the challenges of rapid global environmental change. What we did was to couch the more technical information and conceptual models arising from environmental sciences in the language and context of philosophy and religion, the social sciences and the creative arts and professional studies (e.g. business, commerce, engineering and medicine). As instructors, it was our perception that by doing so we made our technical content more accessible to the average, non-science undergraduate student. We modeled for the students how one can make connections and that one should get curious about these concepts and explore and apply them to their own particular contexts. We reinforced students making connections independently by listening to the student's explanation of the connection and why it is appropriate to their context. We deliberately started with this approach in the first lecture and built upon it throughout the semester until the students became comfortable with making and articulating these connections on their own. This is, essentially, the basis of the final group project and is the foundation of the "cocktail party conversation" learning goal.

One avenue for students to begin making their own connections occurred at the beginning of each class, during which the instructors shared and briefly discussed relevant current events. After the first week of class, the instructors frequently received unsolicited emails from students with recent news pieces and topics for discussion. By sharing these with the class, we reinforced students' curiosity and motivation to seek out interesting topics and identify connections between real-world events and course content.

A primary means of prompting students to independently make connections to course content, as well as interact relationally with their classmates and instructor(s) was in-class group activities. In approximately half of class meetings, groups averaging eight students were assigned by counting off to twenty and students were required to move to assemble with classmates sharing their number. One of the ways that the instructors took advantage of the large lecture hall space was to point to general areas of the room for the groups to form and left it to the students to get organized. Initially, the process required a good deal of cajoling from the instructors, but students quickly became comfortable with the process and made the transition efficiently. Groups were generally allowed fifteen minutes to discuss and answer a short series of questions while the instructors circulated throughout the room to be present with each group and, when necessary, facilitate discussion. In-class activities generally focused either on application of a concept from lecture in new ways, or on responding to an assigned reading or video. Following the group discussion period, the instructors led a brief re-cap with the full class by soliciting answers from the different groups. During this time, we could encourage further discussion between groups who 
may have responded differently to the prompt, and, importantly, gauge student understandings and offer feedback to correct misconceptions. Perhaps more importantly, these group activities also provided venues for instructors to engage with students on a more personal level than would be possible behind a lectern. We found one welcome outcome of such an approach to be the reinforcing (or in some cases the reconfiguration) of the notion of the nature of a professor-student relationship.

When group activities focused on alternative perspectives, often introduced through readings or videos, the activities became an avenue for grappling with cognitive dissonance. During group discussions and the re-cap discussions that followed, we allowed students to refine their conceptions of ecological and socio-ecological systems. Throughout, the instructors provided hands-on mentoring to act as guides to the iterative process of creating an understanding, sharing that understanding, defending that understanding in the face of questions and then reconfiguring that understanding as the generated information is re-communicated. We found that this approach propelled students toward the critical thinking required to accommodate new ideas and entertain other possible ways of being. In this way, we differed somewhat from a pure interpretation of constructivism and followed an approach of creating a continuum of engagement that may be thought of along the lines of an educational guild (Swap \& Wayland, 2014).

To the extent that we do use lecture as a teaching tool, we reject the attitude of the "sage on the stage" approach, leveling-to the extent possible-the classroom hierarchy and opening the exchange of knowledge and opinions among all those present. This is often embodied through small but symbolic actions: for instance, moving out from behind the podium and out into aisles and between the rows of the larger classroom. Moving throughout the lecture hall helps to make the class feel smaller by not allowing people to "hide" in the back and also symbolizes a greater degree of openness between student and professor by deconstructing the physical space that can become a barrier to interaction. We also make a point of frequently pausing to read faces and to invite questions (e.g. Bannink \& Van Dam, 2013b), and polling the class to gauge their knowledge, opinions, and degree of engagement. These moments of "taking the pulse" of the class have allowed the instructors to tailor class time, for example to reinforce a poorly understood concept or to build upon an example that engendered strong student response. We aimed to carry ourselves and to foster relationships in such a way that students became comfortable in approaching us and ultimately in accessing a variety of educational resources available to them (instructors, coinstructors, reference librarians, speakers/seminar series, as well as using the internet more broadly).

When lecturing, we used call-and-response and poll-style questions to encourage the attention of a large group of students, while other questions allowed individuals to share an answer or an opinion. We choose to use a 'show of hands' rather than clickers for these types of questions. Although clickers have some advantages with respect to the ability to quickly collect data, we are conscious of two key points: their monetary cost to students, and the placement of yet another inanimate object between student faculty interactions; it is our opinion that using a show of hands is more intimate and personally engaging. One type of question that we have found particularly effective in engaging students is to ask where students are from or had visited, and to use the students' own geographic knowledge of a place or a system (e.g. proximity to the Chesapeake Bay, Blue Ridge Mountains, the coastal beaches, etc.) to help illustrate a point. Doing so reflects our "asset based" approach of building off of existing knowledge and skills, often showing students that they knew more than they thought merely through their own personal experiences. It is important to note here that the types of questions that we ask in this setting are more open-ended 
and designed to gauge experience and knowledge of context rather than questions that had a definitive 'right/wrong' answer in the context of factual knowledge for the course. Furthermore, it was our experience that the numbers and diversity of those raising their hands increased over the course of the semester.

In our hybrid method, we frequently used class time to actively discuss learning materials read or viewed outside of class. This would more typically be found in a small seminar-style course, and is consistent with the flipped classroom approach, although in our experience such elements are rarely found in a large ecology course. The group activities used in this course also bore some resemblance to Peer Instruction (Mazur, 1997). Groups of students worked interactively to reach consensus on conceptual questions, and re-cap sessions allowed the instructor to assess understandings immediately. However, our activities differed from a more typical form of Peer Instruction (PI) in that PI uses smaller groups (three to four students) and questions interspersed throughout a lecture rather than all at once. The two methods are likely to produce similarly positive results, although one potential advantage of our method is that randomly assigning groups forced students to interact with more of their classmates throughout the semester than if groups had been formed based on proximity.

\section{Evaluation of Students}

Evaluation of students was based on two mid-term exams, a final exam, the final project, class participation and attendance, and extra credit. Different modes of evaluation are appropriate for the assessment of different learning goals and using multiple methods allowed the instructors to assign grades based on a more holistic criteria that goes beyond a student's ability to "spit back" facts and includes indicators of critical thinking and engagement (Fink, 2003; Nilson, 2010). Midterm exams were given during the first two-thirds of the course and consisted of approximately 70 multiple-choice questions each. Although multiple-choice questions are best suited to evaluating factual knowledge, in order to elicit higher-level understandings, we also crafted questions that required students to apply concepts in novel situations; for example, students were asked read a scenario and relate it to a theoretical concept in the study of environmental resilience known as the adaptive cycle. The final exam was similar in format to the midterm exams, consisting of multiple-choice questions focusing on content from the last third of the course; hence, the majority of questions covered the final project presentations. The final projects were graded based on a combination of instructor perceptions of the overall quality of the group oral presentation and short paper, instructor perceptions of individual performance, as well as student evaluations of team member contributions. Class participation and attendance were assessed based on a combination of in-class activities and instructor perceptions of aspects of student participation, for example asking/answering questions or volunteering opinions during lecture and recap of in-class activities.

Opportunities to earn extra credit were announced during class, with credit being awarded to students who took the initiative to attend lectures and other educational events relevant to but outside of the course. Students could propose additional activities that they thought were applicable for extra credit by contacting an instructor with supporting intellectual rationale prior to the activity, allowing students a further opportunity to exercise their agency and build equity in the learning process. To receive credit, students were required to spend at least one hour at the event and to produce a coherent one-page summary and reflection on the event. The amount of extra credit earned was at the discretion of the instructors. 


\section{Evidence of Effectiveness}

This case study being motivated by recently observed trends in the discourse surrounding large introductory courses such as the one we describe, we did not approach our course with consideration toward collecting data regarding the efficacy of our teaching methods. However, quantitative and qualitative data available to us, such as anonymous, on-line, end of term, student course evaluations, can offer some insight into the value of our methods (Emery et al., 2003, Feldman, 1977; Wachtel, 1998). That said, we are limited in the strength of conclusions we can draw regarding how effectively our approach leads to improvements in student engagement or learning. Despite these constraints, which are discussed in greater detail below, in this section we use a selection of quantitative and qualitative data to support the assertion that our course has effectively engaged students.

End-of-term student evaluations, developed by the institution, are made available to all students for all courses at the University of Virginia. Student ratings from those completed evaluations indicate that the course instructor(s) and overall course compare favorably to the cohort mean (Figure 2). Here, the cohort is considered to include all other courses at the undergraduate level taught in the same department for the same semester. Course evaluations used the Likert scale and were implemented institutionally during the last several weeks of each semester. Evaluations were submitted online outside of class and participation was voluntary. Instructor and overall course ratings have improved over time, though it is notable that the lowest course ratings occurred in 2011, when enrollment was largest and the course was taught with a single instructor. We acknowledge that mean scores for our course are not statistically different from cohort averages, and that other comparisons would yield stronger inference regarding the value of our approach - for instance, between sections of the same course taught concurrently using lecture-based and hybrid approaches. However, such data do not exist, and foibles of institutional reporting of course evaluations preclude making other potentially informative comparisons, such as between our course and other introductory-level courses in Environmental Sciences. Moreover, the validity of student evaluations of teaching effectiveness is a topic of debate (Emery et al., 2003; Feldman, 1977; Wachtel, 1998). Thus, we next present additional data supporting the value of our course.

Journal of the Scholarship of Teaching and Learning, Vol. 15, No. 5, October, 2015. 
Instructor Evaluation

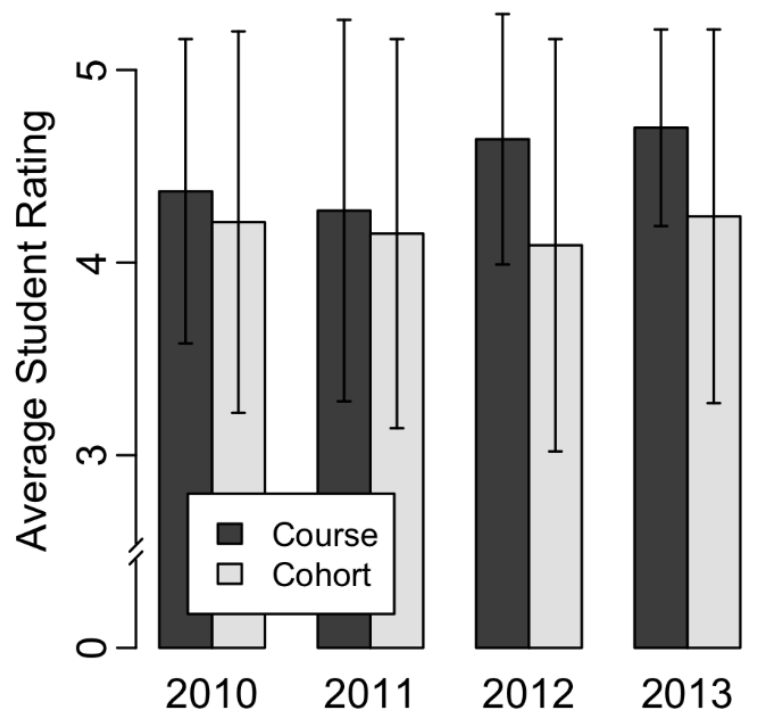

Course Evaluation

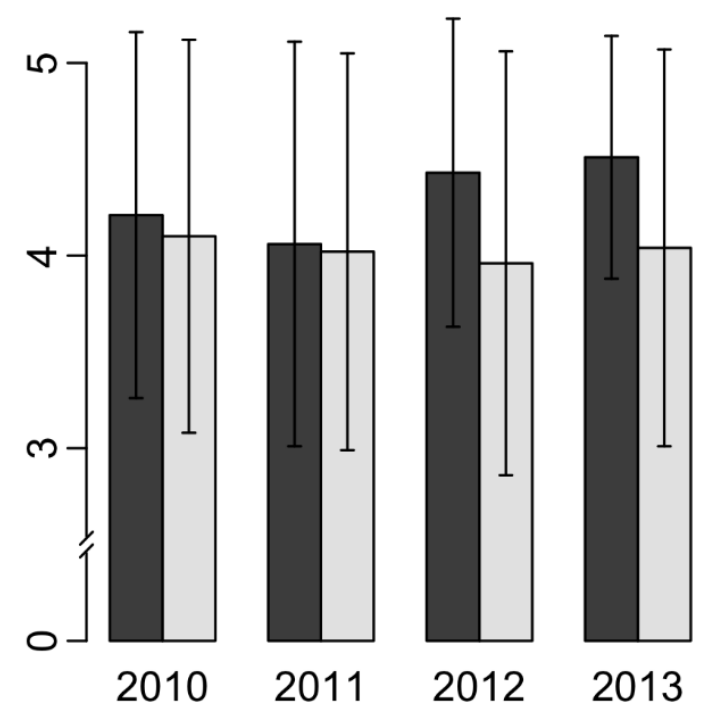

Figure 2: Results of student evaluations for Conservation Ecology: Biodiversity and Beyond taught at the University of Virginia during 2010-2013. "Instructor Evaluation" indicates responses to "overall teaching effectiveness of instructor" and "Course Evaluation" indicates responses to "overall course effectiveness." The evaluation criterion used on a Likert scale: $(5)=$ excellent and $(1)=$ poor. Error bars indicate one standard deviation from the mean. Other courses offered by the department are used for cohort comparison. Response rates for the course were: $89 / 174,86 / 205,85 / 162$, and 82/162 for 2010 to 2013, respectively. Sample sizes for cohort exceeded 1000 responses to each question.

With the on-line, end-of-term student evaluations, respondents had the opportunity to leave anonymous comments in response to a series of questions concerning the course and its instructors. Qualitative responses from those student evaluations indicated a generally high degree of satisfaction with the course and its instructor(s) although such satisfaction was not unanimous. Generally, students commented positively on the efforts of the instructors to engage students, foster meaningful interactions, inspire interest in ecology and the environment, and connect environmental issues to students' lives. Many respondents noted that the instructors and the course were successful in "facilitating interest and participation in a very large class. Group activities and questions kept the class moving and interesting" and that the instructors "thoroughly engaged the entire class." Furthermore, some students asserted that the instructors and their approach "know(s) how to intrigue [their] audience and made [us] want to come to lecture every day!" One student noted that the instructors have "taught me to question everything, see the connections between ideas and variables, and [have] inspired in me a greater curiosity for the world." Yet another student respondent noted how "[the instructors] and the readings really pushed for students to think in different mindsets about the environment, and realize how things are very interconnected at all levels." Some indicated that our course prompted personal growth or a meaningful shift in the way a student thinks about environmental issues. A commonly expressed student sentiment found throughout the anonymous survey responses that seems to corroborate that assertion was that the 
course and its instructors "taught us overall life and academic skills through the class, such as public speaking, how to learn/study effectively, and how we as students are more connected to what is happening around us than we realize" and that they "inspire(s) people to take what they learn and apply it outside of the classroom."

We also measured classroom attendance as an index of student engagement based on participation in-class activities. The logic behind including these statistics is that engaged students are likely to attend class, so high attendance rates should signify high levels of engagement (Handelsman et al., 2005). Although we did not formally take attendance or require students to sign in, students wrote their names on in-class activities to receive credit for their presence and participation. In-class activities were conducted most weeks during the semester (for example, in 2013, activities occurred in eleven out of fifteen weeks), were not announced in advance, and could occur on any day of the week. Thus, participation in these activities is a representative sample of attendance throughout the semester. In 2010 , daily attendance averaged $84.7 \%$ of students, $80.7 \%$ in $2011,83.8 \%$ in 2012 , and $86.1 \%$ in 2013.

We were unable to find directly comparable reports of attendance at the whole-course level in either the literature or records at our own institution; however, the literature on relationships between individual attendance and course performance (Crede et al., 2010), and a study asking whether posting lecture notes online affects class attendance (Hove \& Corcoran, 2008) suggest that average attendance of over $80 \%$ in a course of this size is above the norm, even when attendance is required and/or graded. Although this rate of attendance might be typical in courses with smaller enrollments, such as an upper-level course or even introductory-level courses at many primarily-undergraduate institutions, attendance of this course appears to be high relative to other similarly sized introductory courses.

Taken together, these data are consistent with the assertion that this course and the pedagogical approach taken by the instructors were effective at engendering students' engagement. We reiterate that this evidence must be received cautiously. For example, student course evaluations have been shown to be affected by many factors besides instructor effectiveness (Feldman, 1977; Wachtel, 1998). Using the data available to us, it was not possible to control for such factors, and we are unable to isolate the effect of our pedagogical approach irrespective of other influences. Further study - particularly a designed experiment comparing student outcomes in concurrent class sections taught using traditional vs. our hybrid method-could yield stronger inference. That said, the data do indicate that our course was comparable to and perhaps better than courses offered concurrently in the same department, and that a number of students had strongly positive experiences resulting in substantial engagement and continued interest in conservation ecology.

\section{Discussion: Contextual Factors and Remaining Challenges}

\section{Contextual factors}

Though the course has been largely successful, it has developed throughout its offering and continues to do so. Certain contextual factors that may be somewhat unique to our situation have influenced the development of the course and deserve consideration when adapting our approach to other contexts. An important consideration in applying our approach to other contexts is to what extent this, or any other pedagogy, is appropriate for the learning goals and subject matter of any particular course (Fink, 2003; Nilson, 2010). We feel that one reason for the efficacy of our

Journal of the Scholarship of Teaching and Learning, Vol. 15, No. 5, October, 2015. Josotl.Indiana.edu 
approach is that we are able to model key conceptual themes in our course, for example connectedness, transdisciplinarity, and the adaptive cycle, in the way we teach. In this way, our content and approach are mutually reinforcing, but a different subject matter may suggest different approaches to engaging students and demonstrating important themes. We encourage others to intelligently borrow from our approach and others that encourage active learning and to continually evaluate, adjust, and experiment to find the approach that best suits each instructor and course. Relying on quantitative indicators, assessments planned a priori, and designed experiments, not merely instructor intuition, is encouraged.

In any course, the student body has a wide-ranging influence. In our context, we have found that University of Virginia students are generally beneficiaries of great access to resources and as a result are generally skilled and intellectually engaged, at least in their chosen field of study. As a result, it has been our experience that they often enter a course having high potential for making connections, and a powerful tool for motivating our students has been to tap into existing areas of engagement by drawing connections to those fields. Other bodies of students may have differences in skill and engagement, and strategies for increasing student engagement in learning should be tailored to the characteristics of the students. In spite of the opportunities afforded by the academic skill and engagement of University of Virginia students, this does present a challenge. Namely, we find that student thinking can be "siloed" in their field of study and is sometimes infected with a degree of intellectual arrogance. Furthermore, as discussed in Allen et al., (2014) and Swap \& Wayland (2014), there is a strong tendency among many of our students to be product focused even at the expense of not understanding process. These patterns of thought must be challenged and a degree of "unlearning" must take place to allow students to then consider alternative perspectives and make the sort of diverse connections that the course asks of them; hence, our emphasis on cognitive dissonance. One question that arises is what is the source of this narrowmindedness, and to what degree the academic environment and other modes of instruction foster it.

\section{Remaining Challenges}

In spite of the growing popularity of active learning pedagogies, there are still broader challenges to implementing them. Accordingly, we pose three "big questions" which we offer some perspectives on based on our understandings and experiences: 1) How big is too big for a course like this to work? 2) How many instructors does it take to effectively teach a large-enrollment introductory college course? and 3) Do institutions see value in this type of approach, or will schools continue to tend toward predominantly didactic forms of instruction?

How big is too big? Though our approach increased the interactivity of a large lecture course, it was still stressed by large enrollments. It is likely not coincidence that we received the lowest average course evaluation in fall of 2011 when enrollment was largest. A key way in which we were able to interact personally with students was by briefly visiting with each group during in-class activities. It was our experience that an increase in class size on the order of $25 \%$ led to an increase in both the number of student groups and students in them as well as a reduction in both the time an instructor can spend with each group as well as in the student-student interactions within the group. Taking into account improvements made as our approach developed, the course appeared to be most successful with enrollments under 180 students, but further adaptations could facilitate interactions in even larger class sizes.

Journal of the Scholarship of Teaching and Learning, Vol. 15, No. 5, October, 2015. Josotl.Indiana.edu 
How many instructors? The issues of "how many instructors" and "how big is too big" seem related given the apparent importance of face time. We partly overcame the strain of large enrollment by adding an experienced graduate teaching assistant as a co-instructor in 2013 . The co-instructor was present throughout the course, lecturing, facilitating activities, and meeting with students, and we suggest that the addition of a co-instructor may have led to increases in student learning and engagement given that course ratings were highest in the year with two instructors (2013). Since face time appears to be critical, adding instructors should increase the number of students able to be effectively taught in a given course section, but some consideration should be given to the level of instructor: an experienced undergraduate or inexperienced graduate student can likely help facilitate group work and offer students extra help, but may not be able to share responsibilities for lecturing, designing activities, and writing exams. An added benefit of having multiple experienced instructors is that each will inevitably have different strengths and areas of expertise, which can increase the breadth of knowledge instructors are able to share with students. This may be especially effective in courses such as ours that explicitly focus on connections within and across disciplines.

Do institutions see the value? Individual instructors often have considerable ownership over how they teach their courses, but without institutions seeing the value of more studentcentered or constructivist pedagogies for improving student learning and engagement, didactic, lecture-based courses are likely to continue their dominance in higher education. Others have noted how resistance to instructional innovation can be driven by misconceptions about the effectiveness of the approach (Rogers, 2003; Gess-Newsome et al., 2003; Bunce et al., 2008; Mulryan-Kyne, 2010; Seymour et al., 2011). With respect to our own context both the instructor and co-instructor have been recognized by the institution's teaching resource center for their efforts in classroom instruction and pedagogical innovation. With that said, however, the question as to whether the home department and its school see this approach as both parsimonious and adding value remains open.

Under a certain paradigm, it can be viewed as economical and efficient means to maximize the numbers of students, causing us to wonder whether educational institutions, at the level of individual departments on up, see the value in teaching innovations. Challenges arising from such a scenario may be exacerbated if expectations on research or institutional service leave little time or incentive for professors to invest in their teaching. Our experience suggests that this sort of an approach may not optimally leverage all existing assets to improve student learning and engagement.

\section{Conclusions}

Although there is some pessimism in higher education and many challenges to engaging students in large-enrollment introductory college courses, we illustrate in this case study a hybrid approach, combining elements of traditional lecture and student-centered social constructivist pedagogies, that we argue has been effective in our context and could inspire adaptation to other institutions and course subjects. Other studies support the effectiveness of hybrid approaches (Carrió et al., 2011; Chase et al., 2013), and even suggest that students may prefer these approaches (Minhas et al., 2012). Our own data, though limited, are consistent with the assertion that the development of this particular approach has led to improvements in student engagement. We also assert that hybrid approaches may be attractive because they could be easier to implement than wholesale adoption of a new pedagogical method and serve as a means for faculty to experiment with new tools while 
not straying too far into the unknown. Our approach relied on five key features that were reflected in multiple aspects of our course, and which we believe not only individually promote engagement but are also mutually reinforcing: 1) use of small-group activities to facilitate student-student and student-instructor interactions in the classroom; 2) consideration of multiple perspectives and knowledge sources through the use of a diversity of instructional media; 3) leveling of the classroom hierarchy to invite broader participation; 4) creation of cognitive dissonance as a platform for engagement; and 5) high instructor availability to create opportunities for face-to-face interaction.

\section{Acknowledgements}

The authors thank C. Berinyuy, L. Intolubbe-Chmil, K. Wayland, and four anonymous reviewers for their insightful comments that greatly improved the manuscript.

\section{References}

Allen, N., Boots, R., Bugas, M., Parsons, A., \& Swap, R. (2014). Student voices: Arriving as strangers, welcomed as friends: Student reflections on mindsets, equity, and partnerships in international service-learning. Journal of Community Engagement and Scholarship 7 (1), [online] URL: $\quad$ http://jces.ua.edu/student-voices-arriving-as-strangers-welcomed-as-friends-studentreflections-on-mindsets-equity-and-partnerships-ininternational-service-learning/

Bannink, A., \& Van Dam, J. (2013a). The first lecture: Playing upon identities and modeling academic roles. Linguistics and Education, 24 (4), 556-571.

Bannink, A., \& Van Dam, J. (2013b). Voices, grins and laughter in the lecture room. Linguistics and Education, 24 (4), 572-584.

Barker, D. (2004). The scholarship of engagement: A taxonomy of five emerging practices. Journal of Higher Education Outreach and Engagement, 9 (2), 123-137.

Bell, S. (2010). Project-based learning for the 21st century: Skills for the future. The Clearing House, 83 (2), 39-43.

Bergmann, J., \& Sams, A. (2012). Flip Your Classroom: Talk To Every Student In Every Class Every Day. Alrington, VA: ISTE.

Biggs, J. (1999). What the student does: teaching for enhanced learning. Higher Education Research \& Development, 18 (1), 57-75.

Bishop, J. L., \& Verleger, M. A. (2013). The flipped classroom: A survey of the research. In ASEE National Conference Proceedings, Atlanta, GA.

Boyer, E. (1996). The scholarship of engagement. Journal of Public Service and Outreach, 1 (1), 11-20.

Journal of the Scholarship of Teaching and Learning, Vol. 15, No. 5, October, 2015.

Josotl.Indiana.edu 
Bunce, D. M., Havanki, K., \& VandenPlas, J. (2008). POGIL in the High School Chemistry Classroom. In R. S. Moog and J. N. Spencer (Eds). Process Oriented Guided Inquiry Learning (POGIL). Washington, D.C.: American Chemical Society.

Carlson, S. (2014) “A Caring Professor May Be Key in How a Graduate Thrives," The Chronicle of Higher Education, retrieved September 19, 2014 at http://chronicle.com/article/A-CaringProfessor-May-Be-Key/146409/

Carrió, M., Larramona, P., Banos, J. E., \& Pérez, J. (2011). The effectiveness of the hybrid problem-based learning approach in the teaching of biology: a comparison with lecture-based learning. Journal of Biological Education, 45 (4), 229-235.

Chase, A., D. Pakhira, \& M. Stains. 2013. Implementing process-oriented, guided-inquiry learning for the first time: adaptations and short-term impacts on students attitude and performance. Journal of Chemical Education, 90, 409-416.

Christenson, S. L., Reschly, A. L., Appleton, J. J., Berman-Young, S., Spanjers, D. M., \& Varro, P. (2003). Best practices in fostering student engagement. Best Practices in School Psychology 5, 1099-1120.

Conway, C. J. (2014). Effects of Guided Inquiry versus Lecture Instruction on Final Grade Distribution in a One-Semester Organic and Biochemistry Course. Journal of Chemical Education, $91(4), 480-483$.

Crede, M., Roch, S. G., \& Kieszczynka, U.M. (2010). Class attendance in college: A meta-analytic review of the relationship of class attendance with grades and student characteristics. Review of Educational Research, 80 (2), 272-295.

Crow, M. M. (2010). Organizing teaching and research to address the grand challenges of sustainable development. BioScience, 60 (7), 488-489.

Cuseo, J. (2007). The empirical case against large class size: adverse effects on the teaching, learning, and retention of first-year students. The Journal of Faculty Development, 21 (1), 5-21.

Dym, C. L., Agogino, A. M., Eris, O., Frey, D. D., \& Leifer, L. J. (2005). Engineering design thinking, teaching, and learning. Journal of Engineering Education, 94 (1), 103-120.

Eberlein, T., Kampmeier, J., Minderhout, V., Moog, R. S., Platt, T., Varma-Nelson, P., \& White, H. B. (2008). Pedagogies of engagement in science. Biochemistry and Molecular Biology Education, 36 (4), 262-273.

Ebert-May, D., Brewer, C., \& Allred, S. (1997). Innovation in large lectures: Teaching for active learning. Bioscience, 47 (9), 601-607.

Emery, C. R., Kramer, T. R., \& Tian, R. G. (2003). Return to academic standards: a critique of student evaluations of teaching effectiveness. Quality Assurance in Education, 11 (1), 37-46.

Journal of the Scholarship of Teaching and Learning, Vol. 15, No. 5, October, 2015.

Josotl.Indiana.edu 
Feldman, K. A. (1977). Consistency and variability among college students in rating their teachers and courses. Research in Higher Education, 6 (3), 223-274.

Fink, L. D. (2003). Creating significant learning experiences: An integrated design approach to designing college courses. Jossey-Bass/Wiley, San Francisco, CA.

Gess-Newsome, J., Southerland, S. A., Johnston, A., \& Woodbury, S. (2003). Educational reform, personal practical theories, and dissatisfaction: The anatomy of change in college science teaching. American Educational Research Journal, 40 (3), 731-767.

Gibbs, G. (1992). Control and independence. In G. Gibbs and A. Jenkins (Eds.), Teaching Large Classes in Higher Education, How to Maintain Quality with Reduced Resources. London: Kogan Page.

Gidley, J. M. (2012). Futures of Education for Rapid Global-Societal Change. In F. Gonzalez (Ed.) There's a Future: Visions for a Better World. Madrid, Spain: BBVA.

Handelsman, M. M., Briggs, W. L., Sullivan, N., \& Towler, A. (2005). A measure of college student course engagement. The Journal of Educational Research, 98 (3), 184-191.

Hein, S. M. (2012). Positive impacts using POGIL in organic chemistry. Journal of Chemical Education, 89 (7), 860-864.

Herreid, C. F., \& Schiller, N. A. (2013). Case studies and the flipped classroom. Journal of College Science Teaching, 42 (5), 62-66.

Hornsby, D. J., Osman, R., \& De Matos Ala, J. (2013). Teaching large classes: Interdisciplinary perspectives for quality tertiary education. Stellenbosch: SUN Media.

Hove, M. C., \& Corcoran, K. J. (2008). If you post it, will they come? Lecture availability in introductory psychology. Teaching of Psychology, 35 (2), 91-95.

Jones, R. D. (2008). Strengthening student engagement. International Center for Leadership in Education, 1 .

Klem, A. M., \& J. P. Connell. (2004). Relationships matter: linking student support to student engagement and achievement. Journal of School Health, 74 (7), 262-273.

Lave, J. \& Wenger, E. (1991). Situated Learning: Legitimate Peripheral Participation. Cambridge: Cambridge University Press.

Lesgold, A. M. (1984). Acquiring Expertise. In J. R. Anderson and S. M. Kosslyn (Eds.), Tutorials in learning and memory: Essays in honor of Gordon Brewer. San Francisco: W. H. Freeman. 
Mazur, E. (1997). Peer Instruction: A User's Manual. Series in Educational Innovation. Upper Saddle River, NJ: Prentice Hall.

Minhas, P. S., Ghosh, A., \& Swanzy, L. (2012). The effects of passive and active learning on student preference and performance in an undergraduate basic science course. Anat. Sci. Educ. 5, 200-207.

Moog, R. S., \& Spencer, J. N. (2008). POGIL: An overview. In ACS symposium series (Vol. 994, pp. 1-13). Oxford: Oxford University Press.

Mulryan-Kyne, C. (2010). Teaching large classes at college and university level: Challenges and opportunities. Teaching in Higher Education, 15 (2), 175-185.

Nilson, L. B. (2010). Teaching at its best: A research-based resource for college instructors. Third edition. San Francisco, CA: Jossey-Bass/Wiley.

Nisbet, M. C., Hixon, M. A., Moore, K. D., \& Nelson, M. (2010). Four cultures: new synergies for engaging society on climate change. Frontiers in Ecology and the Environment, 8 (6), 329331.

Opdecam, E., Everaert, P., Van Keer, H., \& Buysschaert, F. (2014). Preferences for Team Learning and Lecture-Based Learning Among First-Year Undergraduate Accounting Students. Research in Higher Education, 55 (4), 400-432.

Prosser, M., \& Trigwell, K. (2014). Qualitative variation in approaches to university teaching and learning in large first-year classes. Higher Education, 67 (6), 783-795.

Richlin, L. (2001). Scholarly Teaching and the Scholarship of Teaching. New Directions For Teaching \& Learning (86), 57-68.

Rogers, E. M. (2003). Diffusion of Innovations (5th ed). New York: Free Press.

Savery, J. R., \& Duffy, T. M. (1995). Problem based learning: An instructional model and its constructivist framework. Educational Technology, 35 (5), 31-38.

Savery, J. R. (2006). Overview of problem-based learning: Definitions and distinctions. Interdisciplinary Journal of Problem-based Learning, 1 (1), 9-20.

Seymour, E., DeWelde, K., \& Fry, C. Determining Progress in Improving Undergraduate STEM Education: The Reformers' Tale. A white paper commissioned for the forum, Characterizing the Impact and Diffusion of Engineering Education Innovations, February 7-8, 2011; National Academy of Engineering of the National Academies: Washington, DC, 2011. http://www.nae.edu/File.aspx?id=36664 (accessed Feb 2013).

Swap, R. J., \& Wayland, K. (2014). Working across disciplines and chipping away at silos with SLCE: An interdisciplinary approach to educating science and engineering students. International 
Journal for Service Learning in Engineering, Humanitarian Engineering and Social Entrepreneurship, 120-136.

Thomas, J. W. (2000). A review of research on project-based learning. Retrieved November, 14, 2015 from http://bie.org/index.php/site/RE/pbl_research/29.

Umbach, P. D., \& Wawrzynski, M. R. (2004). Faculty do matter: The role of college faculty in student learning and engagement. Paper presented at the annual forum of the Association for Institutional Research, Boston, MA.

Vygotsky, L. S. (1978). Mind in Society: The Development of Higher Mental Processes. Cambridge: Harvard University Press.

Wachtel, H. K. (1998). Student evaluation of college teaching effectiveness: A brief review. Assessment and Evaluation in Higher Education, 23 (2), 191-212.

Whitmer, A., Ogden, L., Lawton, J., Sturner, P., Groffman, P. M., Schneider, L., Hart, D., Halpern, B., Schlesinger, W., Raciti, S., Bettez, N., Ortega, S., Rustad, L., Pickett, S. T. A., \& Killilea, M. (2010). The engaged university: providing a platform for research that transforms society. Frontiers in Ecology and Environment, 8 (6): 314-321.

Woods, D. R. (2013). Problem-Oriented Learning, Problem-Based Learning, Problem-Based Synthesis, Process Oriented Guided Inquiry Learning, Peer-Led Team Learning, Model-Eliciting Activities, and Project-Based Learning: What Is Best for You? Industrial \& Engineering Chemistry Research, 53 (13), 5337-5354.

Yarime, M., Trencher, G., Mino, T., Scholz, R. W., Olsson, L., Ness, B., Frantzeskaki, N., \& Rotmans, J. (2012). Establishing sustainability science in higher education institutions: towards an integration of academic development, institutionalization, and stakeholder collaborations. Sustainability Science, 7 (1), 101-113.

Journal of the Scholarship of Teaching and Learning, Vol. 15, No. 5, October, 2015.

Josotl.Indiana.edu 